\title{
Relationship between clinical presenting patterns of acute myocarditis and oedema and late enhancement extension
}

\author{
Alberto Roghi ${ }^{2}$, Daniela Lanza ${ }^{3}$, Patrizia Pedrotti ${ }^{2}$, Angela Milazzo ${ }^{2}$, Ornella Rimoldi ${ }^{1,{ }^{*}}$, Stefano Pedretti ${ }^{2}$ \\ From 15th Annual SCMR Scientific Sessions \\ Orlando, FL, USA. 2-5 February 2012
}

\section{Summary}

Acute myocarditis clinical onset can span from subclinical disease to acute heart failure, fatal arrhythmias or sudden cardiac death. Patients with more severe clinical onset have larger areas of inflammation and contrast enhancement which are directly correlated with left ventricular systolic function.

\section{Background}

acute myocarditis (AM) clinical onset can span from subclinical disease to acute heart failure (AHF) ventricular fibrillation (VF) or sudden cardiac death in young adults. Myocarditis can underly the aetiology of other cardiomyopathies (CM) such as dilated CM arrhythmogenic left or right ventricle CM. Aim of the study was to evaluate the relationship between myocardial oedema and late enhancement (LGE) extension and clinical presenting patterns of acute myocarditis by means of cardiac magnetic resonance imaging (CMR).

\section{Methods}

Eighty-two consecutive patients (pts) referred for suspected myocarditis from 2007 to 2010 were retrospectively analyzed. Symptoms, ECG changes, reduced myocardial function, elevated creatine kinase, positive troponin T, suggested AM. Coronary artery disease was excluded at angiography. Patients were studied on days $\mathrm{x} \pm \mathrm{y}$ after the onset of symptoms The diagnosis was confirmed by CMR (Siemens Avanto 1.5 Tesla) according to the presence of typical signal hyperintensity at Short Tau Inversion Recovery (STIR) images, associated with concordant LGE $(0.1 \mathrm{mmol} / \mathrm{Kg}$ gadobutrol) distribution .
The area of enhancement on STIR and CE-IR images were measured by commercial software and expressed as percentage of the LV. Data are $x \pm S D$, significant difference $\mathrm{p}<0.05$.

\section{Results}

According to the initial clinical picture pts were divided into two groups: group $1(\mathrm{G} 1 ; \mathrm{n}=68)$, presenting with chest pain; group 2 (G2; 14 pts), presenting with AHF or VF. Haemodynamic and functional parameters were similar in the 2 groups (Table), in G2 EF was slightly lower. G2 showed a larger area of oedema on STIR images and LGE distribution. LVEF was significantly correlated both to STIR $(\mathrm{R}=0.49 \mathrm{p}<0.0001)$ and LGE $(\mathrm{R}=0.4 \mathrm{p}<0.0006)$ percentages.

\section{Conclusions}

Pts with AM presenting with AHF or VF at admission showed significantly larger percentage of oedema and of LGE. Our data suggest a direct relationship between the severity of clinical presentation and the extension of myocardial damage.

\section{Funding}

Department of Cardiology, Niguarda Ca'Granda Hospital, Milan, Italy.

\section{Author details}

${ }^{1}$ IBFM Centro PET Settore C, CNR, Milano, Italy. ${ }^{2}$ CMR Unit Dept of Cardiology, Niguarda Ca'Granda Hospital, Milan, Italy. ${ }^{3}$ Cardiology, University of Verona, Verona, Italy.

Published: 1 February 2012

IIBFM Centro PET Settore C, CNR, Milano, Italy

Full list of author information is available at the end of the article

(C) 2012 Roghi et al; licensee BioMed Central Ltd. This is an open access article distributed under the terms of the Creative Commons Attribution License (http://creativecommons.org/licenses/by/2.0), which permits unrestricted use, distribution, and reproduction in any medium, provided the original work is properly cited. 
Table 1

\begin{tabular}{cccc}
\hline & Group 1 & Group 2 & $p$ \\
\hline Age & $31 \pm 11$ & $38 \pm 11$ & 0.046 \\
Female & $13 \%$ & $29 \%$ & 0.15 \\
LV EDV (ml/m2) & $76 \pm 15$ & $71 \pm 17$ & 0.20 \\
LVESV(ml/m2) & $28 \pm 10$ & $30 \pm 13$ & 0.5 \\
LV EF(\%) & $64 \pm 8$ & $58 \pm 14$ & 0.13 \\
LV mass (g) & $148 \pm 36$ & $164 \pm 44$ & 0.155 \\
RV EF(\%) & $62 \pm 6$ & $61 \pm 11$ & 0.662 \\
STIR+ percentage (\%) & $9 \pm 7$ & $33 \pm 23$ & $<0.0001$ \\
LGE percentage (\%) & $8 \pm 6$ & $19 \pm 20$ & 0.047 \\
Pericardial effusion & $29 \%$ & $50 \%$ & 0.136 \\
\hline
\end{tabular}

doi:10.1186/1532-429X-14-S1-P185

Cite this article as: Roghi et al:: Relationship between clinical presenting patterns of acute myocarditis and oedema and late enhancement extension. Journal of Cardiovascular Magnetic Resonance 2012 14(Suppl 1): P185.

Submit your next manuscript to BioMed Central and take full advantage of:

- Convenient online submission

- Thorough peer review

- No space constraints or color figure charges

- Immediate publication on acceptance

- Inclusion in PubMed, CAS, Scopus and Google Scholar

- Research which is freely available for redistribution

Submit your manuscript at www.biomedcentral.com/submit
C Biomed Central 